\title{
The effect of myasthenia gravis as a prognostic factor in thymoma treatment
}

\author{
Bulent Aydemir \\ Dr. Siyami Ersek Thoracic and Cardiovascular Surgery Training and Research Hospital, Istanbul, Turkey
}

\begin{abstract}
OBJECTIVE: Thymoma is a standard epithelial tumor. Though it is rare, it constitutes $50 \%$ of anterior mediastinal masses. Variety of immunological diseases may accompany thymoma; however, myasthenia gravis (MG) is the most frequently associated paraneoplastic syndrome. Most effective treatment for thymoma is complete surgical resection. In this study, impact of MG on prognosis of thymoma cases was examined.
\end{abstract}

METHODS: Records of 61 patients who underwent surgery with diagnosis of thymoma between January 2003 and September 2016 were retrospectively reviewed. All cases were analyzed for data related to age, gender, complaint, localization of lesion, surgical procedure, histopathological diagnosis, stage, MG, and long-term follow-up results.

RESULTS: Total of 58 cases were included in the study. Of those, 37 patients were male and 21 were female. Mean age was 48 years. While 24 cases of thymoma were accompanied by MG, 34 cases were not. Duration of follow-up ranged from 1 month to 155 months.

CONCLUSION: It was found that in group with MG, 5 -year survival rate was $87.5 \%$ while it was $82.4 \%$ in group without MG. Despite longer duration of survival in group of thymoma associated with MG, there was no significant statistical difference between groups $(p=0.311)$.

Keywords: Myasthenia gravis; thymectomy; thymoma.

$\mathrm{T}$ hymoma is a standard epithelial tumor. Although it is rare, it constitutes $50 \%$ of anterior mediastinal tumors [1]. Its annual incidence is $0.5 / 100.000$ [2]. Thymoma may be seen at any age. It has observed in patients aged 8 months to 90 years; however, average age at onset is 53 years [3]. Most patients are aged between 40 and 60 years at diagnosis, and no gender difference has been noted in frequency of the disease [2]. Ninety-five percent of thymomas are found at anterior mediastinum [4].

At present, etiological factors of thymoma are not known. Thymoma typically grows slowly, and may show local invasion. Metastasis is generally seen on pleura pericardium or diaphragm; extrathoracic metastasis is rarely seen [5]. Even after complete resection, thymoma demonstrates tendency to local recurrence [6].

One-third of thymoma cases do not manifest any 
TABLE 1. World Health Organization histopathological classification of thymomas

Type A Oval or spindle cell thymoma demonstrating little nuclear atypia associated with or without a few lymphocytes Type AB Thymoma rich in lymphocytes and with characteristic features of Types A and B

Type B1 Thymoma containing numerous lymphocytes and patchy areas of medulla with normal thymic activity

Type B2 Thymoma containing numerous lymphocytes, marked or lack of medullary differentiation foci

Type B3 Thymoma containing round or polygonal epithelial cells that exhibit no or mild atypia and minor component of lymphocytes

Type C A definite cytologic atypia and a set of histologic features no longer specific to the thymus (thymic carcinoma)

TABLE 2. Masaoka staging system

Stage I Encapsulated tumor without microscopic or macroscopic capsular invasion

Stage IIA Microscopic capsular invasion

Stage IIB Macroscopic invasion of mediastinal fatty tissue and/or mediastinal pleura

Stage III Macroscopic invasion of neighboring organ (pericardium, major vessels and/or lungs)

Stage IVA Pleural and/or pericardial spread

Stage IVB Lymphogenous and/or hematogenous metastasis

clinical symptoms. Clinical symptoms develop due to compression, expulsion, or infiltration of adjacent organs as result of growing tumor. Symptoms such as pain, coughing, hoarseness, shortness of breath, vena cava superior syndrome, and weight loss may occur, depending on location of the tumor [4].

Treatment of thymoma varies according to factors such as clinical appearance, presence of encapsulation, and invasion of surrounding tissues [7]. Complete surgical resection is most effective method. However, in stage III and IVA thymoma, due to circumstances such as presence of local invasion of neighboring organs and diffuse pleural or pericardial implants, surgical success cannot always be achieved [8]. In case of advanced stage thymoma, adjuvant radiotherapy [9] or chemotherapy [10] is suitable treatment method.

Most important prognostic factors for thymoma involve clinical staging of the patient, histopathological classification, and complete resection of the tumor. Various diseases have been associated with thymoma. These include hematological syndromes, red cell aplasia, Hashimoto's thyroiditis, immune deficiency syndromes, and bone and kidney dis- eases [4]. Myasthenia gravis (MG) is the most frequently seen autoimmune disease associated with thymoma. MG is an autoimmune neuromuscular junction disease. Weigert first demonstrated possible association between MG and thymic tumors in 1901. In 1939, Blalock reported that remission can be achieved in a patient with a thymic tumor [11]. MG has been observed in association with $25 \%$ to $59 \%$ of thymoma cases [12]. Though worse prognosis has been claimed for cases of thymoma associated with MG, many other authors have advocated against this assertion [13].

The present study is examination of impact of presence of MG on prognosis of patients with thymoma.

\section{MATERIALS AND METHODS}

Records of 61 patients who underwent surgery for diagnostic and therapeutic purposes related to thymoma at Dr. Siyami Ersek Thoracic and Cardiovascular Surgery Training And Research Hospital Clinic of Thoracic Surgery between January 2003 and September 2016 were retrospectively analyzed. 
TABLE 3. Characteristic features of the cases, with and without myasthenia gravis MG

\begin{tabular}{|c|c|c|c|c|c|}
\hline \multirow[t]{2}{*}{ Factors } & \multicolumn{2}{|c|}{ Cases associated with MG } & \multicolumn{2}{|c|}{ Cases not associated with MG } & \multirow[t]{2}{*}{$\mathrm{p}$} \\
\hline & $\mathrm{n}$ & $\%$ & $\mathrm{n}$ & $\%$ & \\
\hline Number of patients & 24 & 41.4 & 34 & \multirow[b]{2}{*}{$54.18(23-84)$} & \\
\hline Age (years) & \multicolumn{2}{|c|}{$41.5(13-62)$} & & & $\begin{array}{l}0.106 \\
0.200\end{array}$ \\
\hline \multicolumn{6}{|l|}{ Gender } \\
\hline Female & 11 & 45.58 & 10 & 29.4 & \\
\hline Male & 13 & 54.2 & 24 & 70.6 & \\
\hline Symptomatic & 24 & 100 & 20 & 58.8 & \\
\hline Tumor size $(\mathrm{cm})$ & \multicolumn{2}{|c|}{$5.68(2-11)$} & \multicolumn{2}{|r|}{$8.46(3-16)$} & 0.102 \\
\hline Method & & & & & 0.307 \\
\hline Sternotomy & 20 & 83.3 & 26 & 76.5 & \\
\hline Thoracotomy & 3 & 12.5 & 8 & 23.5 & \\
\hline VATS & 1 & 4.2 & 0 & 0 & \\
\hline Masaoka stage & & & & & 0.062 \\
\hline I & 7 & 29.2 & 8 & 23.5 & \\
\hline II & 14 & 58.3 & 16 & 47.1 & \\
\hline III & 2 & 8.3 & 9 & 26.5 & \\
\hline IV & 1 & 4.2 & 1 & 2.9 & \\
\hline WHO histological classification & & & & & 0.026 \\
\hline B2 & 14 & 58.3 & 10 & 29.4 & \\
\hline B3 & 6 & 25 & 5 & 14.7 & \\
\hline$A B$ & 1 & 4.2 & 7 & 20.6 & \\
\hline B1 & 2 & 8.3 & 9 & 26.5 & \\
\hline A & 1 & 4.2 & 3 & 8.8 & \\
\hline Resection & & & & & 0.419 \\
\hline Ro & 19 & 79.2 & 31 & 91.2 & \\
\hline R1 & 3 & 12.5 & 2 & 5.9 & \\
\hline R2 & 2 & 8.3 & 1 & 2.9 & \\
\hline
\end{tabular}

MG: Myasthenia gravis; VATS: Video-assisted thoracic surgery; WHO: World Health Organization.

Cases were divided into 2 groups: thymoma patients with and without associated MG. Groups were compared with regard to patient gender, histological type of thymoma, type of surgical procedure, and long-term follow-up results.

Cases were staged based on Masaoka staging system, while histological type was determined according to World Health Organization (WHO) histopathological classification system (Table 1,2) [4]. Preoperative diagnosis was made, and treat- ment was performed based on analysis of clinical files and pathology reports; physical examination; chest radiograms; computed thoracic tomograms, and in some cases, positron emission tomographic/ computed tomographic examinations; fine-needle aspiration biopsy; and mediastinotomy. Biopsy procedures were performed under radiographic guidance. All patients underwent detailed neurological examination for MG, and medical treatment for the patients with MG was determined based on treatment protocols of neurology clinics. Potential intra- 


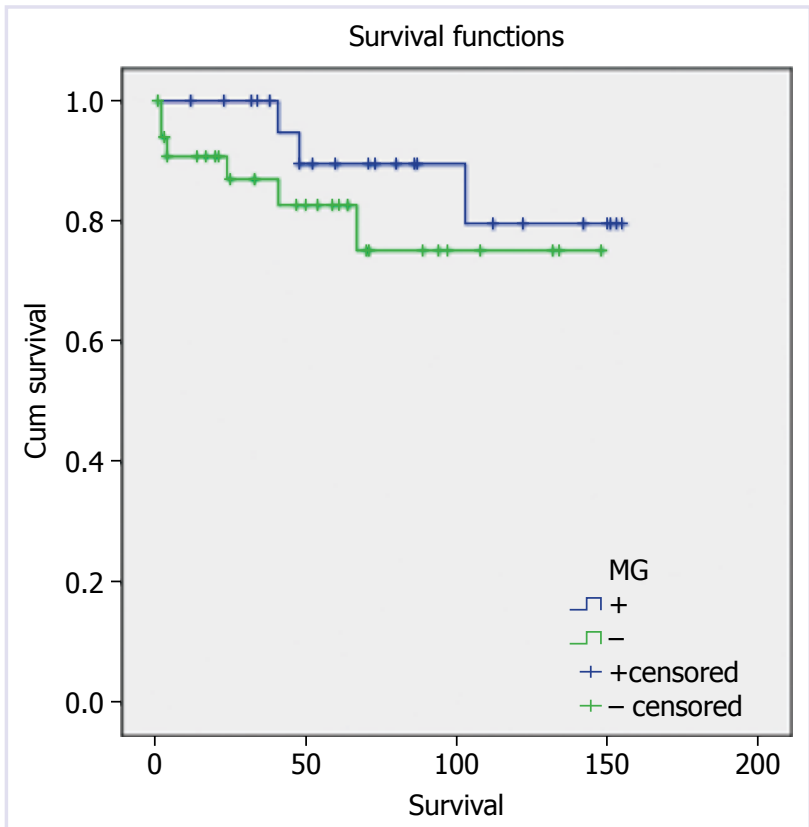

FIGURE 1. Analysis of overall survival in cases of thymoma with or without MG.

and postoperative complications were explained, and approval of the patients was obtained.

Standard monitoring procedures (e.g., measurement of invasive blood pressure, body temperature, end-tidal carbon dioxide and oxygen concentration, neuromuscular block, electrocardiographic monitoring, pulse oxymetry) were performed for all patients post surgery. Procedure performed was median sternotomy, posterolateral thoracotomy, or video-assisted thoracic surgery. Mass was resected with thymic tissue and mediastinal fat tissue. For cases of Masaoka stage III or IV, other involved tissues were also resected.

Monitoring of patients during early postoperative stage included obtaining daily posterior-anterior chest radiogram and performing hemograms, biochemical tests, and clinical assessment of health status. No change in medical treatment was made during early postoperative period.

For comparison between categorical values, Pearson's chi-square test and Fisher's exact test were used. Survival rates were calculated based on clinical and histopathological data, surgical resection, Masaoka stage, and MG criteria according to
Kaplan-Meier method. Comparisons between survival curves were performed using log-rank test. $\mathrm{P}$ value $\leq 0.05$ was accepted as statistically significant. Survival was calculated from date of surgery to last day of follow-up period. SPSS Statistics 21.0 (IBM Corp., Armonk, NY, USA) software was used to perform analyses.

\section{RESULTS}

In our clinic, total of 61 patients underwent surgical procedure related to thymoma between 2003 and 2016. Three patients who had biopsy only were excluded. A total of 58 (male: $n=37,63.8 \%$; female: $n=21,36.2 \%)$ patients with mean age of $48.93 \pm 2.141$ years (range: $13-84$ years) were included in the study. MG was associated with thymoma in 24 cases, while in 34 cases, only thymoma was detected (Table 3). In cases without MG, shortness of breath was the most frequently seen symptom. Lethargy, pain, weight loss, and swelling of the neck were among other symptoms encountered.

Cases of thymoma with MG were followed-up over period of between 12 and 155 months (median: 83.96 months). Five-year survival rate was $87.5 \%$. Follow-up of cases without MG ranged between 1 and 149 months (median: 52.18 months), and 5 -year survival rate was $82.4 \%$ (Figure 1 ). No statistically significant difference was found between the 2 groups $(p=0.311)$ (Figure 1$)$.

Relationship between Masaoka stage and WHO histological classification in cases with and without associated MG was also analyzed. Mortality rates were highest in stage I and III. Masaoka stage I and II thymomas were mostly found WHO type B2, stage III and IV were type B2 and B3. Mortality rates in cases of thymoma associated with and without $M G$ were $12.5 \%$ and $17.6 \%$, respectively (Table 4).

\section{DISCUSSION}

Thymoma is the most frequently encountered anterior mediastinal tumor. Two-thirds of patients are asymptomatic, and diagnosis is often made based on routine examinations and tests. Fifty percent of 
TABLE 4. Correlation between Masaoka stage and WHO histological classification

WHO histological classification

Group

$\frac{\text { Masaoka stage }}{\mathrm{n}} \quad \frac{\text { Total }}{\mathrm{n} \quad \%}$

\begin{tabular}{lllll} 
B2 & B3 & B1 & AB & A \\
\hline$n$ & $n$ & $n$ & $n$ & $n$
\end{tabular}

Mortality

Associated with MG

Not associated with MG

$\begin{array}{ccccccccc}\text { I } & 7 & 29.2 & 4 & 1 & 0 & 1 & 1 & 1 \\ \text { II } & 14 & 58.3 & 10 & 2 & 2 & 0 & 0 & 1 \\ \text { III } & 2 & 8.3 & 0 & 2 & 0 & 0 & 0 & - \\ \text { IV } & 1 & 4.2 & 0 & 1 & 0 & 0 & 0 & 1\end{array}$

$\begin{array}{ccccccccc}\text { I } & 8 & 23.5 & 2 & 1 & 2 & 2 & 1 & 2 \\ \text { II } & 16 & 47.1 & 4 & 3 & 5 & 3 & 1 & 1 \\ \text { III } & 9 & 26.5 & 3 & 1 & 2 & 2 & 1 & 3 \\ \text { IV } & 1 & 2.9 & 1 & 0 & 0 & 0 & 0 & -\end{array}$

MG: Myasthenia gravis; WHO: World Health Organization.

symptomatic cases are associated with a paraneoplastic neurological syndrome, and most frequently it is MG. Neurological findings of MG play key role in investigation of thymic pathologies such as thymoma [14]. In this study, $58.8 \%$ of the cases not associated with MG were symptomatic.

Thymoma is observed in both male and female patients generally aged between 40 and 50 years of age, without difference in gender distribution [15]. In the present study, median age of the patients was 49 years, and no difference in distribution was observed according to gender. In thymoma group without associated $\mathrm{MG}$, male patients were more numerous than women.

There is currently no standardized system for staging of thymoma in the literature. Though type of resection, presence of $\mathrm{MG}$, and advanced age have been reported as prognostic factors, prognosis of thymoma has primarily been based on Masaoka stage and WHO histological classification [16]. Masaoka staging system is anatomical classification first described in 1981 and subsequently revised in 1994. It uses criteria of invasion of peripheral organs, completeness of resection, association of thymoma with $\mathrm{MG}$, tumor size, and involvement of major vessels. It is presently the most widely accepted and most used staging system for treatment approach. Since 1999, histological classification system of WHO has also been accepted and used worldwide. According to this system, thymomas are divided into 2 main groups based on the shape of neoplastic epithelial cells or their nuclei which are oval and dendritic shapes define type $A$ and type $B$ accordingly. Type $B$ tumors are divided into 3 subtypes of B1, B2, and B3. Type AB tumors combine these 2 morphologies. Any type of thymic carcinoma cases are classified as type C [17].

All histological types except type A of thymoma may be seen in cases with associated MG. Type B2 is most frequently observed thymoma type in patients with $\mathrm{MG}$ [18]. Okumura et al. reported that type $A$ and type $C$ thymomas were not seen in cases with $\mathrm{MG}$, while types $\mathrm{AB}(6.8 \%), \mathrm{B} 1$ (40\%), B2 $(55.6 \%)$, and $\mathrm{B} 3(10 \%)$ were seen in respective percentage of cases [19]. In the present study, type A thymoma was encountered in only 1 case with $\mathrm{MG}$, while types B1, B2, and B3 were detected in $8.3 \%$, $58.3 \%$, and $25 \%$ of cases, respectively.

It is very difficult to describe prognostic factors for thymoma. The fundamental reason is its rarity 
and polymorphic structures. Presence of MG complicates diagnosis and treatment of thymoma further. MG is observed in $\geq 30 \%$ of patients with thymoma, and thymoma is detected in approximately $10 \%$ to $15 \%$ of cases of MG [20].

In the literature, impact of MG on prognosis for thymoma is controversial. Though earlier studies reported presence of $\mathrm{MG}$ as an indicator of poor prognosis, recent publications have demonstrated that presence of MG may not affect prognosis or that, in fact, these thymoma patients may have a better prognosis [21]. Outcomes of study performed by Wang et al. in 2016 demonstrated that MG exerts favorable impact on long-term results of thymoma and that patients with thymoma with associated MG survive longer [22]. Various studies have shown that cases with MG have better prognosis due to early onset of myasthenic symptoms. Filosso et al. detected an association between MG and early Masaoka stage, which was explained by early diagnosis of thymoma as result of MG [23]. Elmac1 et al. demonstrated that survival rates were markedly higher in cases with myasthenic thymomas diagnosed at early stage, and their recent studies have substantiated this finding [24]. In present study, $87.5 \%$ of cases with associated MG were in early stage of the disease (Masaoka stages I and II), while $70.6 \%$ of thymoma cases not associated with MG were diagnosed in early stage of the disease. In addition, 5-year survival rates were higher in the group associated with $\mathrm{MG}$ relative to thymoma alone group.

Conflict of Interest: None declared.

Financial Disclosure: The authors declared that this study has received no financial support.

Authorship contributions: Concept - B.A.; Design - B.A.; Supervision - B.A.; Materials - B.A.; Data collection \&/or processing - B.A.; Analysis and/or interpretation - B.A.; Literature search - B.A.; Writing - B.A.; Critical review - B.A.

\section{REFERENCES}

1. Schmidt-Wolf IG, Rockstroh JK, Schuller H, Hirner A, Grohe C, Muller-Hermelink HK, et al. Malignant thymoma: current status of classification and multimodality treatment. Ann Hematol 2003;82:69-76.
2. Wilkins KB, Sheikh E, Green R, Patel M, George S, Takano M, et al. Clinical and pathologic predictors of survival in patients with thymoma. Ann Surg 1999;230:562-74. Crossre.

3. Engels EA, Pfeiffer RM. Malignant thymoma in the United States: demographic patterns in incidence and associations with subsequent malignancies. Int J Cancer 2003;105:546-51. Crossre.

4. Metin, SK, Timik tümörler. Mediyasten Hastalıkları ve Cerrahisi. Bölüm 32, TÜSAD Eğitim Kitapları Serisi 2015;281-99.

5. Gray GF, Gutowski WT III. Thymoma. A clinicopathologic study of 54 cases. Am J Surg Pathol 1979;3:235-49. Crossree

6. Ruffini E, Mancuso M, Oliaro A, Casadio C, Cavallo A, Cianci $\mathrm{R}$, et al. Recurrence of thymoma: analysis of clinicopathologic features, treatment, and outcome. J Thorac Cardiovasc Surg 1997;113:55-63. Crossre

7. Kuzucu, A, Liman, T, Taştepe, İ, Demircan, S, Soysal, Ö, Erkal, HS, et al. Treatment and prognosis in patients with thymoma. Turkish J Thorac and Cardiovasc Surg 2000;8:793-6.

8. Ichinose Y, Ohta M, Yano T, Yokoyama H, Asoh H, Hata K. Treatment of invasive thymoma with pleural dissemination. J Surg Oncol 1993;54:180-3. Crossret

9. Batata MA, Martini N, Huvos AG, Aguilar RI, Beattie EJ. Thymomas: Clinicopathologic features, therapy, and prognosis. Cancer 1974;34:389-96. Crossret

10. Chahinian P, Bhardwaj S, Meyer RJ, Jaffrey IS, Kirschner PA, Holland JF. Treatment of invasive or metastatic thymoma: Report of eleven cases. Cancer 1981;47:1752-61. Crossre-

11. Wilkins EW, Edmunds LH, Castleman B. Cases of thymoma at the Massachusetts General Hospital. J Thorac Cardiovasc Surg 1966;52:322-30.

12. Lewis JE, Wich MR, Scheithauer BW, Bernatz PE, Taylor WF. Thymoma: a clinicopathologic review. Cancer 1987;60:2727-43.

13. Okumura $M$, Ohta $M$, Tateyama $H$, Nakagawa K, Matsumura A, Maeda $\mathrm{H}$, et al. The world health organization histologic classification system reflects the oncologic behavior of thymoma. Cancer 2002;94:624-32. Crossret

14. İşeri P, Komsuoğlu S. Timoma ve nörolojik hastalıklarla ilişkisi. Available at www.toraks.org.tr. Accessed September, 1, 2016.

15. Griffith RC. Thymus gland. IN Anderson's Pathology. The CV Mosby Co; 1985.

16. Sarihan S, Bayram AS, Gebitekin C, Yerci Ö, Özkan L. Thymic tumors and outcomes after radiotherapy. Turk J Oncol 2013;28:59-66. Crossref

17. Blalock A, Mason MF, Morgan HJ, Riven SS. Mgravis and tumors of the thymic region: report of a case in which the tumor was removed. Ann Surg 1939;110:544-61. Crossret

18. Okumura M, Miyoshi S, Fujii Y, Takeuchi Y, Shiono H, Inoue $\mathrm{M}$, et al. Clinical and functional significance of WHO classification on human thymic epithelial neoplasms: a study of 146 consecutive tumors. Am J Surg Pathol 2001;25:103-10. Crossre:

19. Elmacı T, Tireli E, Barlas S, Toker A, Dayığlu E, Deymeer F, et al. Surgical approaches in thymomas. Türk Göğüs Kalp Damar Cerrahisi Dergisi 1994;2:375-8.

20. Zhang Z, Cui Y, Jia R, Xue L, Liang, H. Myasthenia gravis in 
patients with thymoma affects survival rate following extended thymectomy. Oncol Lett 2016;11:4177-82.

21. Nichols FC, Trastek VF. Standard thymectomy. In: Shields TW, LoCicero J, Reed CE, Feins RH, editors. General thoracic surgery. Philadelphia: Lippincott Williams and Wilkins; 2009. p. 227883.

22. Kondo K, Monden Y. Thymoma and myasthenia gravis: A clinical study of 1,089 patients from Japan. Ann Thorac Surg 2005;79:219-24
23. Wang F, Pang L, Fu J, Shen Y, Wei Y, Tan L, et al. Postoperative survival for patients with thymoma complicating myasthenia gravis-preliminary retrospective results of the ChART database. J Thorac Dis 2016;8:711-7. Crossree

24. Filosso PL, Evangelista A, Ruffini E, Rendina EA, Margaritora $\mathrm{S}$, Novellis $\mathrm{P}$, et al. Does myasthenia gravis influence overall survival and cumulative incidence of recurrence in thymoma patients? A Retrospective clinicopathological multicentre analysis on 797 patients. Lung Cancer 2015;88:338-43. Crossret 